\title{
Systematizing Web Search Through A Meta-Cognitive, Systems-Based, Information Structuring Model (McSIS)
}

Ayman H. Abuhamdieh, Indiana State University, USA Joseph T. Harder, Indiana State University, USA

\begin{abstract}
This paper proposes a meta-cognitive, systems-based, information structuring model (McSIS) to systematize online information search behavior based on literature review of information-seeking models. The General Systems Theory's (GST) prepositions serve as its framework. Factors influencing information-seekers, such as the individual learning styles of Field Independence and Field Dependence (FI/FD); Holist, Serialist (H/S), and Problem-Focused vs. Emotion-Focused $(P F / E F)$ problem-solving approaches, and individual or personal domain knowledge, are incorporated in the model. An example demonstrating the model is presented along with recommendations for educators and researchers.
\end{abstract}

Keywords: Information-Seeking Models; General Systems Theory; Online Information Search

\section{INTRODUCTION}

n online learning pedagogy, students are often directed to search for information in hopes that both the process and product of their search will lead to deeper understanding of the subject domain being searched. Due to the vast amount of information on the Internet and lack of a formal organizing structure, students will almost always use search engines (De Groote, Shultz, \& Blecic, 2014; Henderson, Keogh, \& Eccleston, 2014). In doing so, they typically rely on simple heuristics to find what they need. Often, students' searches are unproductive due to inefficient and/or ineffective searches. Among other factors, search behavior on the Web is impacted by individual cognitive traits and familiarity with the topic domain (Chung, 2012).

Searching for information plays a critical role in students' understanding of a subject. This is well understood by the authors, both of whom have taught distance sections of numerous business courses. Learning by actively investigating a topic is a pedagogy endorsed and even embraced by constructivist teaching advocates (Wilson \& Lowry, 2000). Stated very clearly by one investigator, “... learners develop their own understanding of the topics they study instead of having it delivered by others." (Casas, 2006) This being the case, at least in the context of distance learning, seeking out information on the Web is a pedagogical tool simply too valuable to be ignored.

The World Wide Web (hereafter 'the Web') has evolved into a destination for finding information about all sorts of topics. Finding information about a topic or an issue is more 'Googled' than sought in print. This phenomenon is only expected to grow as information available on the Web multiplies annually and the number of Web-enabled learners surges.

Since the Web became a public domain in the mid-nineties, it became easy to retrieve massive amounts of information (Cheng, Liang, \& Tsai, 2013). This poses a serious multidimensional informational overload problem attributable to personal factors, information characteristics, task and process parameters, and information technology (Harder, 2001). Negative consequences of this overload are significant and include less systematic information search strategies, information omission, lower decision quality, and a higher level of error tolerance (Eppler \& 
Mengis, 2004). These consequences will certainly diminish the quality of learning for a student performing Web searches to enhance his/her understanding of a topic.

The present study builds on literature review to propose a meta-cognitive, systems-based, information structuring model grounded in the system concept of the General Systems Theory (GST). A system is defined as "a set of interacting elements (objects, properties, behaviors, and relationships) that form an integrated whole with a common purpose" (Shah \& Foster, 2014, p.32). General systems theory suggests a set of hierarchical information structuring strata to guide Web information-seekers into refining and organizing their Web search.

Improving information-seeking effectiveness can lead to positive impacts on the quality of Web-based learning. The following sections describe models of information-seeking and search behavior, which are summarized in Table 1, followed by a discussion of the pertinent factors that influence information-seekers. A Metacognitive, Systems-based, Information Structuring Model (McSIS) will be introduced and discussed through an applicatory example. Implications for online educators and researchers conclude the study.

\section{Models Of Information-seeking Behavior}

The information-seeking behavior field is organized into three categories and is represented by a nested model as shown in Figure 1 (Wilson, 1999). In the first category, information behavior acts as the overarching field of research. In the second, information-seeking behavior acts as a subset and embodies models and methods that individuals use to access information resources. The last category - information search behavior - studies user interactions with information retrieval systems. Since this study is proposing a Web information-seeking model, it falls under the information-seeking behavior category.

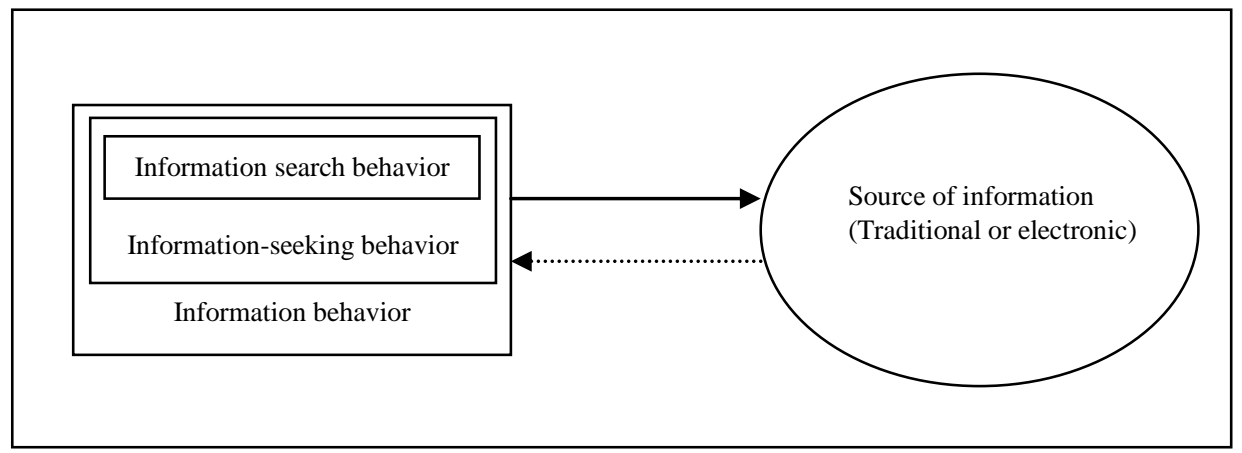

Adapted from: Wilson, T.D. (1999). Models in information behavior research.

Journal of Documentation, 55(3), pp. 249-270.

Figure 1: Nested Model Showing The Relationship Between Information Behaviors And Sources Of Information

Two models discuss information-seeking behavior in a problem-solving context (Dervin, 1983; Wilson, 1999). Dervin's (1983) meta-model explains user information-seeking behavior in terms of an effort to close a gap between a current problematic situation in need of resolution and a desired outcome. Wilson's (1999) model, on the other hand, links the stages that an information-seeker passes through when searching for information, beginning with problem identification, followed by problem definition, problem resolution, and ending with the solution statement. Each of these steps contributes to uncertainty reduction and resolution. Table 1 summarizes the models discussed. 
Table 1: Information-Seeking And Search Model Studies

\begin{tabular}{|l|l|l|}
\hline \multicolumn{1}{|c|}{ Study } & \multicolumn{1}{c|}{ Model } & \multicolumn{1}{c|}{ Emphasis } \\
\hline Wilson (1981) & Information-seeking behavior & Need-based information-seeking behavior \\
\hline Dervin (1983) & Sense-making framework & Problem-solving approach \\
\hline Ellis (1989) & Information-seeking features & Stages of information search \\
\hline Kuhlthau (1991) & Information-seeking stages & Stages of information search \\
\hline Belkin (1995) & Information activity process & Steps followed in information retrieval \\
\hline Wilson (1996) & Information behavior & Macro-information search behavior \\
\hline Ingwersen (1996) & Information retrieval process & Cognitive information-seeking behavior \\
\hline Spink (1997) & Information search process & Interactions in seeking information \\
\hline Wilson (1999) & Information-seeking process & Problem-solving steps/stages \\
\hline Hodkinson\& Kiel (2003) & Web information search & $\begin{array}{l}\text { Personal and technical variables affecting Web } \\
\text { information search }\end{array}$ \\
\hline Lopatovska \& Smiley (2013) & Information behavior & Information behavior in crisis situations \\
\hline
\end{tabular}

Kuhlthau (1993) proposes a stage model of information-seeking behavior. The model consists of six stages: 1) initiation or the beginning of the search process, 2) selection or determination of the exact subject that will be searched, 3) exploration or searching for information about the subject selected, 4) formulation or concentrating on the particulars of the subject matter, 5) collection of relevant information about the subject needing search, and 6) presentation where the search process ends and the results are used.

Related to Kuhlthau's stage model is a 'features' model used to describe individuals' behaviors when searching for information. These features include starting the information search process by asking a friend, for example; then chaining or building on what is known; browsing or performing a semi-structured search; differentiating or filtering the information obtained; monitoring or staying up-to-date with current searches; extracting or separating relevant material from the rest of the information; verifying or assuring the accuracy of the information; and ending or concluding the search (Ellis, 1993).

Ingwersen (1996) explicitly included cognitive elements in the information retrieval process. These include user's work task/interest, current cognitive state, uncertainty, and the problem that needs resolution. These elements interact with the information objects or text/knowledge representations and the information retrieval system settings to formulate a request which translates into a query carried out through an interface or intermediary. This model emphasizes the process aspect of information retrieval and the preconditions, cognitive and otherwise, that work together to produce a query.

Spink (1997) introduced an information search model based on empirical research that represents the search process as constituting several cycles, interactive loops, and user judgments. The model consists of identifying the activities that a user performs when searching for information, such as determining and using search strategies which contain one or more cycles and are search commands used to retrieve information. These cycles could contain feedback used by searchers to judge the search results.

Hodkinson \& Kiel (2003) combine user personal variables (both demographic and behavioral), technical environment, Web search task, and several Web use and experience variables to be factors affecting external information search behavior on the Web, as shown in Figure 2. Variables in the Web experience are the Web usage level, experience, browser skills, Web search skills, Web purchase history, and expected benefits from searching the Web. All these variables arguably influence several Web search factors, whether horizontal (broad) or vertical (depth). The outcomes of this search are expected to affect two sets of variables, one related to the purchase decision and the second to the satisfaction with the search.

Lopatovska \& Smiley (2013) developed an information behavior model in crisis situations using the autoethnographic method. Analysis of the data produced four categories that formed the basis of the model: 1) temporal disaster stage, 2) kind of information needed, 3) information behavior, and 4) information field. The needed information was categorized according to Maslow's hierarchy of needs and the information behavior was divided into three actions: direction information search; active information search; and passive information attainment. 
This study suggests a normative information-seeking model to aid information-seekers in finding the information they need. Before presenting the model and discussing its assumptions, it is important to discuss some of the factors that influence information-seeking behavior.

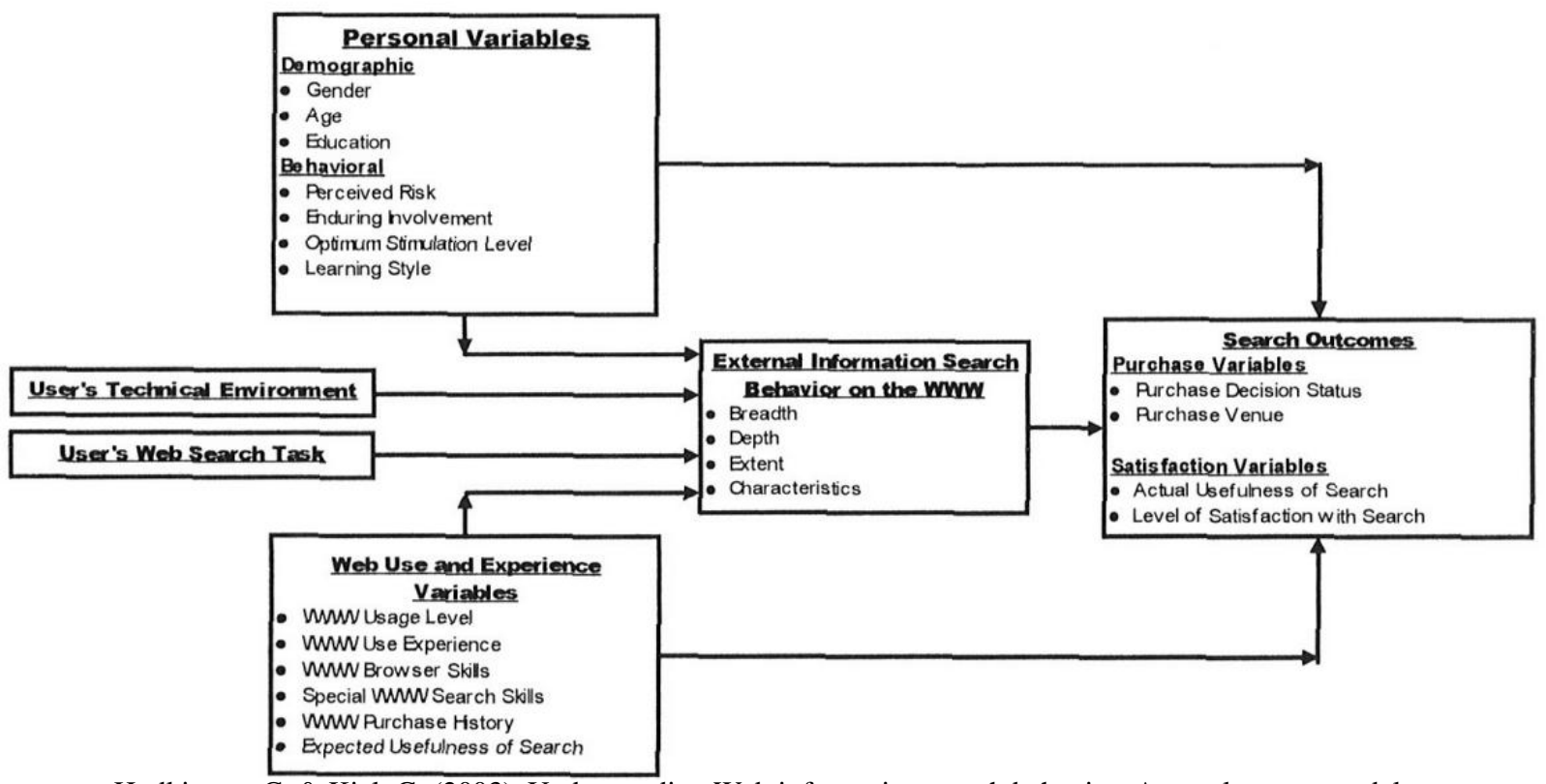

Hodkinson, C. \& Kiel, G. (2003). Understanding Web information search behavior: An exploratory model. Journal of End User Computing, 15(4), pp. 27. Reprinted by permission of Idea Group Inc.

Figure 2: Web-Wide Information Search Model And Its Outcomes

\section{Factors That Influence Information-Seeking Behavior}

Individuals' cognitive abilities, such as spatial thinking, and cognitive styles, such as field dependence and independence, influence their information search performance in different information systems (Kim \& Allen, 2002). A cognitive style refers to a person's individual approach of ordering and processing information (Goldstein \& Blackman, 1978).

One of the most extensively investigated cognitive styles is Field Dependence (FD) vs. Field Independence (FI) learning styles. Field dependent persons are more influenced by their surroundings, while field independent persons overcome the immediate surrounding field and experience objects as separate from their backgrounds (Witkin, 1973). These attributes seems to influence Web searchers where FD users searched the Web in a linear fashion while FI users followed a non-linear approach, which enabled them to find the information they need faster and more efficiently (Palmquist \& Kim, 2000).

Another cognitive style that polarizes individuals along two ends and influences their information-seeking behavior is holists and serialists. Holists perceive their surroundings globally and they tend to have a broad perspective of what they are engaging in to interact with it. They go from global to local. Serialists, on the other hand, build their perceptions of their surroundings in a piecemeal fashion and tend to go from local to global (Pask, 1976a, 1976b). The two perspectives of serialists/holists and FD/FI are matched by many researchers, where FD individuals possess akin cognitive attributes to holists and FI individuals and serialists behave in a parallel fashion when searching for information (Ford \& Chen, 2000).

Problem-solving styles were also found to affect information-searching behavior (Brown, 1991; Wilson, 1999), specifically emotion-focused and problem-focused (Zamble \& Gekoski, 1994). Problem-focused individuals exhibit a nonlinear information-seeking behavior, broadening their search before delving deeper into a particular resource. This is in contrast to the emotion-focused individuals who search linearly and have a narrower and deeper 
initial search focus (Kim, 1999). These two problem-solving styles share similarities with the learning cognitive styles of FD/FI and holists/serialists when seeking information. Field independent, serialist, and problem-focused (FI/S/PF) individuals share similar information-seeking behavioral patters while FD, holists, and emotion-focused (FD, H, EF) individuals are on the other side of this cognitive continuum. Figure 3 syntheses the foregoing three models of these individuals' traits.

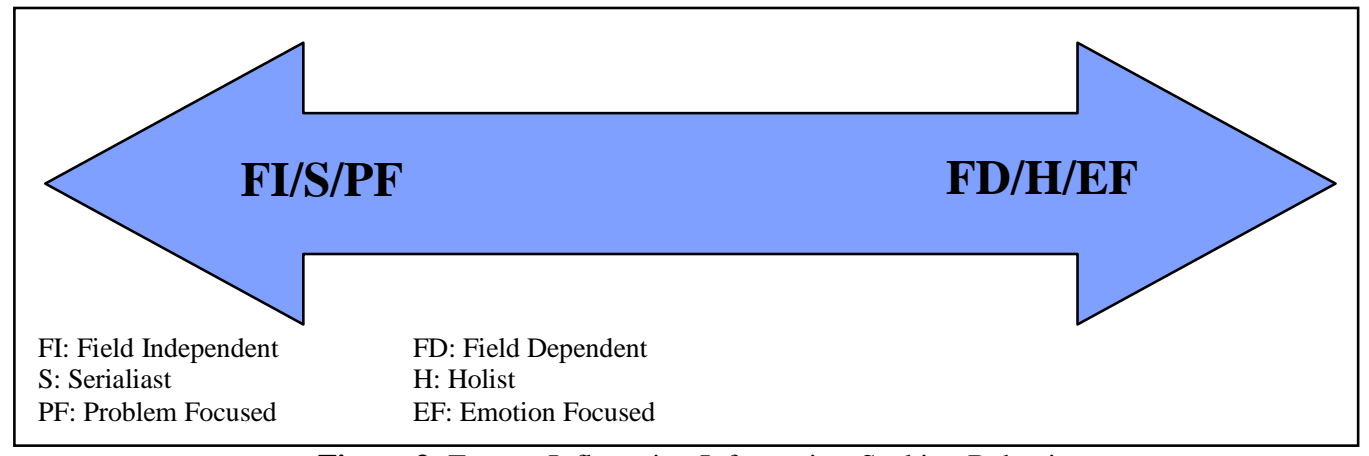

Figure 3: Factors Influencing Information-Seeking Behavior

FI/S/PF cognitive characteristics could be summarized as individuals who prefer induction (from specific to general) rather than deduction. They have analytical perception of facts and events and prefer to structure situations personally rather than have them pre-structured. Their goals and motivations are internal, and they like more than one solution to the problems they encounter. FD/H/EF individuals, on the other hand, prefer deduction (from general to specific). Their perception of facts and events is global rather than analytical and they prefer pre-structured situations. Their goals are defined for them externally and they prefer external motivation. They also prefer a single solution to a problem (Rose, Le Heron, \& Sofat, 2005).

An individual's subject or domain knowledge is one of the important factors related to information search behavior. It refers to the "knowledge of the subject area (domain) that is the focus or topic of the search." (Wildemuth, 2004, p. 246). It is different from the knowledge of search tactics and strategies information-seekers deploy when searching for information (Bates, 1977). Different terms are used to describe the knowledge about a particular issue or topic, such as subject knowledge (Hsieh-Yee, 1993; Vakkari, 2002), topic or factual knowledge (Allen, 1991), and domain knowledge (Bhavnani, 2002; Drabenstott, 2003). This study will adopt the term domain knowledge to denote individuals' subject knowledge about a topic or issue.

The relationship between domain knowledge and information search behavior has been the focus of many earlier studies. Some studies reached an inconclusive result or found no relationship between domain knowledge and information search behavior (Wildemuth, de Bliek, Friedman, \& File, 1995). However, several empirical and theoretical studies found a positive relationship (Bhavnani, 2002; Vakkari, Pennanen, \& Serola, 2003; Wildemuth, 2004). The variables of FI/FD, S/H, PF/EF, and personal domain knowledge are incorporated into the McSIS model. As will be discussed later, these variables influence the way information-searchers traverse the model laterally and vertically. Other factors influencing the information-seeking process, such as the time constraint, technological contextual factors, and other non-personal variables, are not included in the model because the focus is on the individuals' cognitive dynamics rather than other environmental elements.

\section{A Meta-Cognitive Systems-Based Information Structuring Model (McSIS)}

The concept of metacognition was introduced by Flavell (1979), which refers to cognition about cognition or when a person is cognizant of the thinking processes taking place. This cognitive ability ranges form a simple recall process to a complex meta-cognitive introvert dialogue. Hence, when individuals search for information, they are actively cognizant that they are using the model to organize the information retrieved.

The concept of the general systems theory was introduced by Bertalanffy (1968) and is based on the concept of a system which is a set of interrelated components interacting together and act as a whole. The McSIS 
model proposes a hierarchical conceptual structure of an individual's information or conceptualization about topics or issues. Information about topics, objects, and issues are organized in levels/domains. A domain is a set of related objects, topics, or issues that share common characteristics. The model has six assumptions based on the GST and systems thinking (Bertalanffy, 1968; Shah \& Foster, 2014).

1. When devising a topic or an object into smaller or more detailed pieces, one moves into a sublevel/domain.

2. When aggregating topics or objects into a broader context, one moves into a supra-level/domain.

3. Information about topics and objects within a level/domain is related linearly and across levels/domains vertically (supra- and sub-levels/domains). In other words, intra-domain objects and issues are related to other sub- and supra-levels/domains through inter-level/domain relationships.

4. Users are cognizant of their thinking processes when interacting with information.

5. Users possess some knowledge (personal domain knowledge) about the topic searched, ranging from trivial to extensive expertise.

The McSIS model is composed of five levels/domains (Meta, Macro, Meso, Micro, and Nano) and each represents a level/domain in varied degrees of detail or aggregation. As a searcher moves upwards in the model, topics are integrated or aggregated and the level of detail is decreased, while moving downwards increases the level of detail and granularity. The following discussion presents each level/domain.

1. The Meta-level/domain is the highest level/domain in the model and the most encompassing and broadest for the topic that is sought at the meso-level/domain. The person would be at a global perspective and at the highest domain of abstraction. The macro-level/domain is a subsystem of the meta-level/domain.

2. The Macro-level/domain level lies above the meso-level/domain and is broader, encompassing, higherorder, or supra-system of the initial topic. At the macro-level/domain, the topic introduced in the earlier, meso-level/domain, would be a derivative or subsystem. At this level, ties to other subsystems and systems are identified.

3. The Meso-leve/domain is the models' mid-level entry point, where an individual has an idea or a topic which represents the current domain/topic of interest. Topics range from an abstract issue or concept to physical material and objects. The degree of determination or specificity of the topic depends on the individual's personal domain knowledge, which falls on a continuum ranging from minor or superficial to extensive and detailed.

4. The Micro-level/domain. This is a subsystem of the meso-level/domain. The topic is broken into smaller pieces or components for further examination. One of these components or aspects becomes the focus of interest.

5. At The Nano-level/domain, the idea or topic considered in the micro level/domain is further broken down into smaller components. At this level, the degree of specificity is much higher and the topic is a subsystem of the micro-domain. 


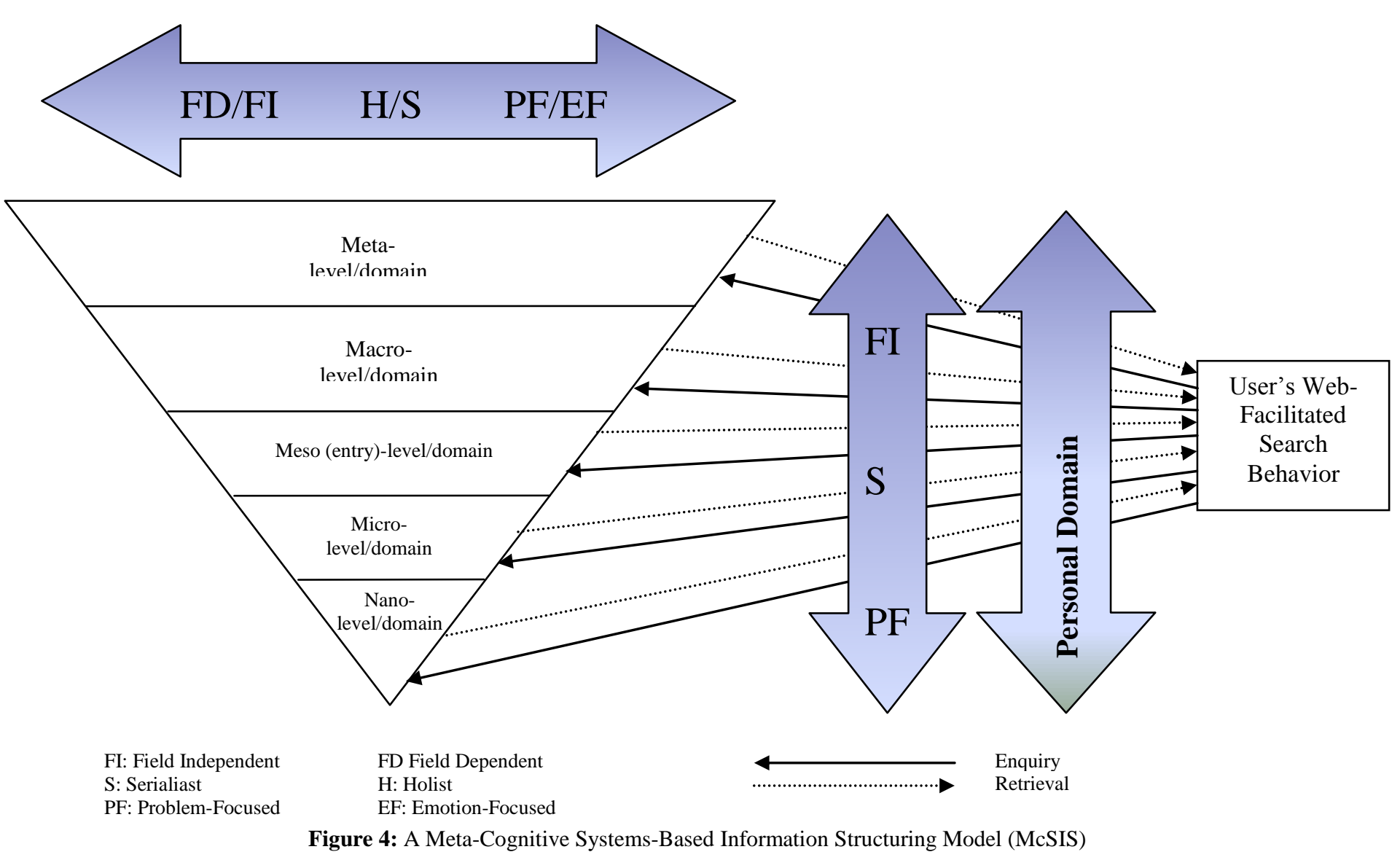


These cognitive learning and problem-solving styles impact individuals' ability to gain new knowledge (Morphew, 2002). Consistent with constructivist theory, individuals learn new material and ideas by building on what they already know, then extend that knowledge to new situations (Liao, 2005; Novak, 1988). This learning is demonstrated in the conversation theory developed by Pask and others (Ford, 2004; Pask, 1976a, 1976b).

Because of the infinite number of topics and issues that could be searched on the Web, a simple example is demonstrated. Suppose an instructor is interested in knowing about the use of participatory technology and its effect on student enthusiasm and class participation. This would be the entry point to the model at the Meso level/domain. Keywords used might simply be "class participation technology." If the information retrieved (dashed arrow in the model) is sufficient, the search terminates. This will be the case where the intent of the search is to explore this topic and read preliminary articles about it.

If more information is needed, an inquiry would be initiated at either the Macro- or the Microlevels/domains or it could stay at the Meso- level/domain, depending on where the investigation is heading. If information is needed about the relationship between the class participatory technology and class size, for example, then the investigation is still at the Meso- level/domain, because the search is about the initial topic and no fragmentation (subsystems) or aggregation (supra-systems) took place to take the inquiry to a different level.

After searching for information about participatory technology and class size, the direction of the inquiry might go to the macro- and meta- levels/domains. Classroom instruction is related to the educational philosophy of an educational institution (a supra system to the classroom). Some institutions focus on the case-based while others focus on the traditional lectures. Each might benefit from a different set of technologies for information delivery, communication and participation. Thus, when the focus moves from a specific class to the institutional level, information search moves to the macro level/domain.

Moving up one level on the model, the Web search continues as long as there is need for further information about the topic at that level. The investigation could take one further step up by comparing educational processes and philosophies across cultures. Each nation has its own philosophy and culture about education and each is at different stage of technological development. When the search turns to national comparability, then the investigation is at the Meta level/domain in this example.

The inquiry might take the opposite direction and go to the micro- and nano- levels/domains. At the microlevel, the class is composed of students, and each has their own differences in terms of gender, age, cognitive ability, intelligence, and other factors. When reaching at the Nano- level, the focus turns to the behavioral and biological factors influencing learning competency and ability. Factors such as which side of the brain one uses to learn and what behavioral activities ignite or stimulate learners would be the focus of the search.

This to-and-fro process would continue until the searcher is satisfied. The personal knowledge about the educational process and educational institutions, in addition to information about individuals' learning abilities and other factors that influence the educational experience, affects the movement vertically or laterally on the model.

\section{IMPLICATIONS FOR ONLINE EDUCATORS}

The purpose of online teaching is to enhance the learning experience of students and improve their ability to assimilate, understand, and apply the course material. Helping them find the information they need, whether related directly or indirectly to a course, is an essential skill that crosses course levels and subjects. The McSIS model is a systematized approach to finding information from the Web that assists in organizing the retrieved results and in reinitiating further searches with closer and better relevance to searcher needs.

Although there is a thrill in going without a guide in an adventure, it could be a difficult experience for online students. In-class teaching is a guided approach to knowledge delivery, where instructors lay out the material they want to cover and carefully guide students to the desired knowledge outcome. Online instruction, on the other hand, has less in-class instructor control. Cognitively organizing a search gives searchers a compass or a guiding 
map that could be used to granulate and navigate the Web's maze. The practice of random keyword generation to find information could be more systematized by organizing the knowledge retrieved from online search engines and generating a better structured search, which is the purpose of the McSIS model.

\section{IMPLICATIONS FOR RESEARCHERS}

This paper proposes a meta-cognitive, system-based information structuring model (McSIS) to systematize users' information search behavior. Researchers can examine the paper and investigate in-depth pertinent personal characteristics or variables that influence users when seeking information and the coordination of these variables. Researchers can also expand the McSIS model and consider different aspects of information-searching behavior as possible outcomes from the different personal characteristics. As users' information-searching skill moves up the learning curve, their skill can affect their search behavior and play an important role in the application of the McSIS model. Other environmental elements, such as the time constraint or technological contextual factors, can also be considered to extend the model. Therefore, the authors believe that the McSIS model can be used as a guide for future research in Web search activities, and this stream of research can also help to enhance users' understanding of information-searching behavior as well as information structuring.

\section{CONCLUSION}

One of today's dilemmas for information-seekers is not the availability of information as much as finding the needed information among the voluminous sources retrieved by online search engines. This study introduces a meta-cognitive, systems-based information structuring model $(M c S I S)$. The model is proposed to systematize information-seeking when searching online. Several end user factors influencing information-seekers are incorporated in the model, such as the continuums of Field-Independence/Field- Dependence (FI/FD), ProblemFocused/Emotion-Focused (PF/EF), Serialists-Holists $(\mathrm{S} / \mathrm{H})$, and the personal domain knowledge. The model is dynamic and treats information retrieval from an end user perspective, where the information-seeker interacts with an information source using this model as a frame of reference to find the sought information.

\section{AUTHOR INFORMATION}

Ayman Abuhamdieh graduated from Rutgers University in 2001 majoring in management information systems and electronic commerce. His research interests include trust in electronic commerce, information systems pedagogy, online information search, and virtual communities. He teaches a wide variety of courses at both graduate and undergraduate levels in the Scott College of Business at Indiana State University. Email: ayman@indstate.edu.

Joseph T. Harder is presently Associate Professor of Management Information Systems in the Scott College of Business at Indiana State University. He came to Indiana State in 1998 after obtaining a Ph.D. in Business Administration from Southern Illinois University. Other degrees held are a Bachelor of Arts in Psychology from Purdue and a Masters in Business Administration from Southern Illinois University. His research interests include assessing learning outcomes in the decision sciences and information systems pedagogy. He currently teaches undergraduate and graduate courses in Management Information Systems, specializing in Data and Knowledge Management. Email: $\underline{\text { Joe.Harder@indstate.edu. }}$

\section{REFERENCES}

1. Allen, B. (1991). Topic knowledge and online catalog search formulation. Library Quarterly, 61(2), 188213.

2. Bates, M. J. (1977). Factors affecting subject catablog search success. Journal of the American society for information science, 28(3), 161-169.

3. Bertalanffy, L. V. (1968). General System Theory: Foundations, Development, Applications. New York: George Braziller, revised edition 1976.

4. Bhavnani, S. K. (2002). Domain-specific search strategies for the effective retrieval of healthcare and shopping information. SIGCHI, Extended Abstracts, 610-611.

5. Brown, M. E. (1991). A general model of information-seeking behavior. Paper presented at the Proceedings 
of the 54th annual meeting of the American Society for Information Science.

6. Casas, M., (2006). Implementing Constructivist Web-Based Learning and Determining its Effectiveness in a Teacher Preparation Course, The Journal of Educators Online, 3(2), 1-17.

7. Cheng, K-H., Liang, J-C., \& Tsai, C-C. (2013). University Students' Online Academic Help Seeking: The Role of Self-Regulation and Information Commitments. Internet and Higher Education, 16, 70-77.

8. Chung, S. (2012). Cognitive and Social Factors Affecting the Use of Wikipedia and Information-seeking. Canadian Journal of Learning and Technology, 38(3).

9. Chung, W., Chen, H., \& Nunamaker, Jr., J. F. (2005). A Visual Framework for Knowledge Discovery on the Web: An Empirical Study of Business Intelligence Exploration. Journal of Management Information Systems, 21(4), 57.

10. De Groote, S. L., Shultz, M., \& Blecic, D. D. (2014). Information-seeking behavior and the use of online resources: a snapshot of current health sciences faculty. Journal of the Medical Library Association, 102(3), 169-176.

11. Dervin, B. (1983). An overview of sense-making research: concepts, methods, and results to date. . Paper presented at the International Communications Association Annual Meeting.

12. Drabenstott, K. M. (2003). Do nondomain experts enlist the strategies of domain experts? Journal of the American Society for Information Science and Technology, 54(9), 836-854.

13. Ellis, D. (1993). Modeling the information-seeking patterns of academic users: A grounded theory approach. Library Quarterly, 63(4), 69-86.

14. Eppler, M. J., \& Mengis, J. (2004). The Concept of Information Overload: A Review of Literature from Organization Science, Accounting, Marketing, MIS, and Related Disciplines. The Information Society, 20, 325-344.

15. Flavell, J. H. (1979). Metacognition and cognitive monitoring: A new area of cognitive developmental inquiry. American Psychologist, 34, 906-911.

16. Ford, N. (2004). Modeling cognitive processes in information-seeking: From Popper to Pask. Journal of the American Society for Information Science and Technology, 55(9), 796-782.

17. Ford, N., \& Chen, S. (2000). Individual differences, hypermedia navigation, and learning: an empirical study. Journal of Educational Multimedia and Hypermedia, 9(4), 281-311.

18. Goldstein, K. M., \& Blackman, S. (1978). Cognitive style: Five approaches and relevant research. New York: John Wiley.

19. Harder, Joseph T. (2001). An Investigation of the Business Value of Automated Underwriting Systems to Mortgage Originators, Doctoral Dissertation, Southern Illinois University.

20. Henderson, E. M., Keogh, E., \& Eccleston, C. (2014). Why go online when you have pain? A qualitative analysis of teenagers' use of the Internet for pain management advice. Child: Care, Health \& Development, 40(4), 572-579.

21. Hodkinson, C., \& Kiel, G. (2003). Understanding Web Information Search Behavior: An Exploratory Model. Journal of End User Computing, 15(4), 27.

22. Hsieh-Yee, I. (1993). Effects of search experience and subject knowledge on the search tactics of novice and experienced searchers. journal of the American Society for Information Science, 44(3), 161-174.

23. Ingwersen, P. (1992). Information retrieval interaction. London: Taylor Graham.

24. Ingwersen, P. (1996). Cognitive perspectives of information-retrieval interaction: elements of a cognitive IR theory. Journal of Documentation, 52(1), 3-50.

25. Kim, K. S. (1999). Searching the Web: Effects of problem-solving style on information-seeking behavior. Paper presented at the World conference on educational multimedia, hypermedia \& telecommunications.

26. Kim, K. S., \& Allen, B. (2002). Cognitive and task influences on web searching behavior. Journal of the American Society for Information Science and Technology, 53(2), 109-119.

27. Kuhlthau, C. C. (1993). Seeking meaning: A process approach to library and information services. Norwood, NJ: Ablex Publishing.

28. Liao, C. (2005). A field study in the externalising of tacit knowledge in on-the-job training. International Journal of Management, 22(1), 79-88.

29. Lopatovska, I., \& Smiley, B. (2013). Proposed Model of Information Behaviour in Crisis: The Case of Hurricane Sandy. Information Research: An International Electronic Journal, 19(1).

30. Morphew, V. (2002). Web-Based Learning and Instruction: A Constructivist Approach, Distance Learning and Technologies: Issues, Trends, and Opportunities. In Khosrow-Pour, M. (ed.), Web Based Instructional 
Learning, (pp. 1-14), IRM Press, Hershey, PA.

31. Novak, J. D. (1988). Learning science and the science of learning. Studies in Science Education, 15, 77101.

32. Palmquist, R., \& Kim, K. S. (2000). Cognitive style and online database search experience as predictors of Web search performance. Journal of the American Society for Information Science, 51(6), 558-566.

33. Pask, G. (1976a). Conversational techniques in the study and practice of education. British Journal of Educational Psychology, 46, 12-25.

34. Pask, G. (1976b). Styles and strategies of learning. British Journal of Educational Psychology, 46, 128148.

35. Rose, E., Le Heron, J., \& Sofat, I. (2005). Student Understandings of Information Systems Design, Learning and Teaching: A Phenomenography Approach. Journal of Information Systems Education, 16(2), 183-195.

36. Shah, M., \& Foster, A. (2014). Undertaking an Ecological Approach to Advance Game-Based Learning: A Case Study. Educational Technology \& Society, 17(1), 29-41.

37. Spink, A. (1997). Study of interactive feedback during mediated information retrieval. Journal of the American Society for Information Science, 48(5), 382-394.

38. Vakkari, P. (2002, March 25-27). Subject knowledge, source of terms, and term selection in query expansion: An analytical study. Paper presented at the Advances in Information Retrieval: 24th BCS-IRSG European Colloquium on IR Research, Glasgow, UK.

39. Vakkari, P., Pennanen, M., \& Serola, S. (2003). Changes of search terms and tactics while writing a research proposal. Information Processing \& Management, 39, 445-463.

40. Wildemuth, B. M. (2004). The effects of domain knowledge on search tactic formulation. Journal of the American Society for Information Science and Technology, 55(3), 246.

41. Wildemuth, B. M., de Bliek, R., Friedman, C. P., \& File, D. D. (1995). Medical students' personal knowledge, searching proficiency, and database use in problem solving. Journal of the American Society for Information Science, 46(8), 590-607.

42. Wilson, B., \& Lowry, M., (2000). Constructivist Learning on the Web, New Directions for Adult and Continuing Education, 88, 79-88.

43. Wilson, T. D. (1981). On user studies and information needs. Journal of Documentation, 37(1), 3-15.

44. Wilson, T. D. (1999). Models in Information Behavior Research. Journal of Documentation, 55(3), 249270.

45. Witkin, H. A. (1973). The role of cognitive style in academic performance and in teacher-student relations. Princeton, NJ: Educational Testing Service.

46. Zamble, E., \& Gekoski, W. L. (1994). Coping. In V. S. Ramachandran (Ed.), Encyclopedia of human behavior (Vol. 2, pp. 1-10). New York: Academic Press. 


\section{NOTES}

